\title{
Study on Kindergarten-Family Cooperation Mode in the Development of Preschool Education
}

\author{
Lina Zhang \\ Teachers' College Shenyang University \\ Shenyang, China
}

\author{
Suoni Zhang \\ Shenyang Radish Education Information \\ Counsel Limited Company \\ Shenyang, China
}

\author{
Xiaodong Pan \\ Teachers' College Shenyang University \\ Shenyang, China
}

2) Promote the mental health development of preschool

Abstract-Families and kindergartens are partners in the development of preschool education. Kindergarten-family cooperation mode has become an inevitable choice for preschool education. This article will analyze the significance of kindergarten-family cooperation, the problems of kindergartenfamily cooperation, the influence factors of kindergarten-family cooperation and the effective operation strategies of kindergarten-family cooperation through literature review and the experience of my own preschool education work, so as to improve the effects of kindergarten-family cooperation mode and to achieve more excellent educational results.

Keywords-Kindergarten-family cooperation mode; Factor; Problem

\section{THE SIGNIFICANCE OF KINDERGARTEN-FAMILY COOPERATION IN THE DEVELOPMENT OF PRESCHOOL} EDUCATION

The kindergartens should first understand the connotation of kindergarten-family cooperation and understand its significance when implementing the kindergarten-family cooperation mode, so as to achieve kindergarten-family cooperation in its true sense and play the role of kindergartenfamily cooperation.

\section{A. Promote the physical and mental development of preschool children}

1) Promote the physical development of preschool children

Preschool children period refers to the children at the age of 3-6 or 7. During this period, the big muscles and small muscles of children develop rapidly, while pen holding skills develop rapidly. At this stage, the combination of families and kindergartens can provide the preschool children with greater movement training space and the opportunity to study systematically, and can help the preschool children to practice more reasonably and grow up healthily. children

With the gradual increase of environmental exploration activities, 3-6, 7 years old children can form a sense of "enterprising" and solve the core of conflict between "enterprising and guilt", which is a kind of identity behavior. Therefore, children at this stage need someone to encourage their enterprising sense and cultivate their sense of responsibility. At this time, teachers and parents need to cooperate with each other and work together to achieve greater results.

\section{B. Improve the educational quality of parents}

1) Understand the laws of the physical and mental development of preschool children

Now most parents of preschool children do not understand the characteristics and laws of physical and mental development preschool children, and cannot give correct guidance in the critical period of preschool children's development. Kindergartens can teach parents the relevant knowledge about the growth of preschool children through parents' meetings, leaflets for parents, telephone, WeChat, QQ and so on according to the situation of parents, so as to improve the parents' parenting level.

2) Update parents' concept of preschool children education, and master scientific parenting methods.

The educational backgrounds of parents are different and the mastered teaching contents are uneven in kindergartens. But, the kindergartens are the places with advanced teaching ideas and teaching methods. Kindergarten-family cooperation can solve the confusion of some parents in the process of education, and let parents master much more and more scientific educational ideas and teaching methods of preschool children, so as to improve the educational quality of parents. 
C. Beneficial to the implementation of the kindergarten teaching tasks

1) Parents cooperate with the task deployment of kindergartens

Kindergartens and families are the places provided for the preschool children to receive education. The kindergartens can let the parents participate in the teaching works of the kindergartens, understand the teaching contents of the kindergartens and master the teaching course of the kindergartens, and then make the parents play a greater role in the course of parents cooperating with the work of kindergartens when kindergartens arrange the teaching tasks, promoting the implementation of teaching tasks of kindergartens more effectively.

\section{2) Tasks arranged by kindergartens is fitted to family} environment

At this stage, the homework assigned by many kindergartens is unified in the whole class, which ensures the consistency of the results but neglects the difference between families. Kindergarten-family cooperation can not only help the kindergartens to take into account the different conditions of the families when arranging tasks, but also improve the participation of families and the quality of completing the kindergarten teaching tasks.

\section{THE PROBLEMS OF KINDERGARTEN-FAMILY COOPERATION IN THE DEVELOPMENT OF PRESCHOOL EDUCATION}

During the period of the Republic of China, there was a concept of families and kindergartens cooperating in preschool education. Starting from the problems encountered in the implementation of kindergarten-family cooperation, it is required to conscientiously analyze and summarize experience to maximize the role of kindergarten-family cooperation.

\section{A. Lower degree of emphasis on kindergarten-family cooperation}

At the present stage, various kindergartens and families have no profound understanding of the kindergarten-family education strategy in all regions, and have not grasped its central idea, and do not realize to combine the "kindergarten" with "family" together, or that the common cooperation was important to the growth of the preschool children and the allround learning development [1].

\section{B. Lack of communication between kindergarten teachers and parents}

The growth of preschool children does not only need the guidance of teachers, but also needs the accompanying of parents. In the kindergarten-family cooperation, the kindergarten teachers lack the communication with the parents, resulting in the parents who have mastered the education methods being unable to communicate with the teachers, and some parents who have no educational experience can only accept the arrangement of the kindergartens unilaterally. It often occurs that kindergarten teachers play a leading role, but ignores the status of parents in activities and the importance of parents to preschool children.

\section{Kindergarten-family cooperation lacks the effective ways of implementation}

The current kindergartens have begun to integrate the concept of kindergarten-family cooperation education and teaching contents, but kindergartens with obvious educational results are still in the minority. According to the literature, it is shown that only $64.7 \%$ of kindergarten teachers are satisfied with their kindergarten-family cooperation and parents hope to further improve [2]. Many parents reflect that the activities organized by kindergartens are only the games, which parents participate in but preschool children can only stand by, so it loses the meaning of parent-child games.

\section{FACTORS THAT INFLUENCE KINDERGARTEN-FAMILY COOPERATION IN THE DEVELOPMENT OF PRESCHOOL EDUCATION}

Kindergartens and families influence the promotion of kindergarten-family cooperation. There are many problems in kindergarten-family cooperation, which requires kindergartens and families to work together to solve. The educational concept of kindergartens, professional quality of teachers, family background of the preschool children, somatological characteristics of the parents and so on will all affect the satisfaction of the parents and teachers on the effect of the kindergarten-family cooperation. This article summarizes the factors that affect the kindergarten-family cooperation into two aspects: the influencing factors of kindergarten and the family background of preschool children.

\section{A. Influencing factors of kindergartens}

\section{1) Educational concept of kindergarten}

Family education and kindergarten education jointly constitute the preschool education. The kindergartens should clearly realize that the family education is the extension of the kindergarten education, and the kindergarten education is the supplement of the family education. The two are not independent of each other and they should take the good growth of the children as the starting point. In the process of cooperation, the cooperation contents, forms and other aspects should be carried out around the core of preschool children, the kindergartens should take the initiative to develop their own professional advantages and play a leading role under the conditions of giving considerations to demands of both sides, and the ultimate goal is to promote the healthy growth of preschool children [7].

\section{2) Professional quality of preschool teachers}

Teachers serve as the guiding role of kindergarten-family cooperation. Professional quality of teachers affects the development and continuation of their kindergarten-family cooperation, thus affecting the preschool education and allaround development of preschool children.

Firstly, the professional quality of teachers' lifelong learning influences the effect of kindergarten-family cooperation. If the teachers do not have the professional 
quality of lifelong learning, do not actively study the connotation of kindergarten-family cooperation, change teaching methods or change teaching ideas, but believe that they are the only executors in children's education, issue orders to parents and do not accept parents' educational ideas and opinions, it will seriously affect the development of kindergarten-family cooperation. Teachers should be able to fully play a leading role in education management, actively guide parents to pay attention to kindergarten-family cooperation, and the ability required to be owned by of educators is to promote the operation of kindergarten-family cooperation.

Secondly, teachers' good teaching ability and the ability to organize and plan activities will affect the progressing effectiveness of the kindergarten-family cooperation. If teachers do not have good work ability, they cannot well integrate kindergarten-family cooperation into the daily activities in the design of teaching activities, which will impede the operation of the kindergarten-family cooperation mode, and ultimately affect the development of preschool children in an all-around way.

Finally, teachers' good communication skills affect the developing effect of kindergarten-family cooperation. Communication is an important prerequisite for kindergartenfamily cooperation. If teachers are poor in communication skills, and cannot communicate with their parents in an equal and respectful way, it will affect the cooperation of parents in their teaching work. For example, in the manual course of super light clays and succulent plants, teachers can assign the plant observation work to children and parents, making them observe together and letting the parents to introduce the characteristics of succulent plants to preschool children, which strengthen the communication between preschool children and parents, so as to promote kindergarten-family cooperation.

\section{B. Family background of preschool children}

Parents of preschool children master the educational methods and educational concepts in different levels. If the parents do not master the scientific education methods or let the children free from the management and control, it will seriously affect the progress of kindergarten-family cooperation and influence the growth and development of the preschool children. In addition, parents' attitudes also affect whether the kindergarten-family cooperation can be carried out smoothly. Only willingness of parents to participate in it can help the kindergarten-family cooperation to work effectively. For example, if some parents let the bad habits of children go unchecked and make preschool children accept different educational ways in the families and kindergartens, resulting that the preschool children will not know whose education should be accepted, thus affecting the development of preschool children.

\section{EFFECTIVE OPERATION STRATEGIES OF \\ KINDERGARTEN-FAMILY COOPERATION MODE IN THE DEVELOPMENT OF PRESCHOOL EDUCATION}

In the face of various types of kindergarten-family cooperation mode, kindergartens should consider their own teaching needs and the family background of preschool children when choosing.

\section{A. Common kindergarten-family cooperation mode}

The kindergarten-family cooperation mode is put forward on the basis of the first-line work experience of educators and long-term theoretical research.

1) Mode of "group of teaching assistants for the growth of preschool children"

It is composed of parents, social elites with professional skills, and other social members with special experiences or interests and hobbies recruited and employed according to the teaching goal of kindergartens [3]. After screening, kindergartens register and create online archives for them, set up posts and specify job responsibilities. The task of the group of teaching assistants is to communicate and discuss with teachers on the scheme of activities before designing the activities by teachers.

2) Mode of "teaching assisting activities of parents"

It is to regularly recruit parents to be teaching assistants and issue a work schedule of parents as teaching assistants. Their work is to invite parents to tell stories to children, teach paintings and play games together with children in the kindergartens, and participate in the design and organization of class teaching activities together with teachers. The purpose is to make up for the lack of kindergarten teachers' skills and change the parents' educational concept [9].

\section{3) "Parents gas station" mode}

Parents can learn the parenting skills and experience through the modules of "bringing up children properly", "baby and I at home", "healthy growth of baby" and so on[10], and record their own doubts in the aspect of education by leaving messages, and teachers can explain according to the problems.

\section{4) Conventional kindergarten-family cooperation mode}

It mainly includes daily communication between teachers and parents, leaflets for parents, parents' corners, family visits, parents' open days, parents' committees, etc. In order to improve the relationship between parents and preschool children and kindergartens, kindergartens can share different forms of parenting experience according to the perplexity about education and teaching reflected by parents.

\section{B. Operation strategy of the kindergarten-family cooperation mode}

1) Learn the connotation of kindergarten-family cooperation

Teachers and parents need to learn the connotation of kindergarten-family cooperation together so as to help each other and cooperate with each other. The connotation of kindergarten-family cooperation includes the concept of kindergarten-family cooperation, the significance of 
kindergarten-family cooperation, the conventional kindergarten-family cooperation mode and so on [4]. Kindergartens should organize to learn the connotation of learning kindergarten-family cooperation mode and use modern technologies to learn at any time by watching videos, meeting online and so on. The connotation of kindergartenfamily cooperation mode should be spread to parents through teachers, so that it can attract the attention of parents and promote the mutual cooperation.

\section{2) Teachers and parents should have unified educational goal}

Preschool education is mainly composed of kindergarten education and family education. Whether it is kindergarten education or family education, its ultimate goal is for the allround development of preschool children. In the operation of the kindergarten-family mode, teachers should specify their educational goals with parents, so as to form the resultant force of education, make children develop rapidly in one direction and accelerate their growth. This is the premise of the operation of the kindergarten-family cooperation mode.

\section{3) Teachers and parents keep communication in time}

The operation of kindergarten-family cooperation mode requires close communication between teachers and parents. With the continuous development and innovation of the current social information technology, the mode of communication between kindergarten teachers and parents is not limited to conventional parents' meetings, family visits or telephone contacts, etc., but also the integration of modern technologies and innovation of the way of exchanging information [5]. For example, more choices can be added for the contact between teachers and parents by setting up WeChat group, installing surveillance video and improving the efficiency of feedback from teachers and parents.

4) Teachers and parents participate in teaching activities together

In the operation of the kindergarten-family cooperation mode, teachers should understand the family background of each preschool child, understand the parents' parenting abilities and knowledge reserves, have pertinent and practical design activities, to ensure that parents have the ability and energy to participate in them, and it is not allowed to design some superficial activities for the kindergarten-family cooperation.

5) Make full use of potential educational resources to enrich teaching contents

Every preschool child's parents have different careers and rich educational resources are hidden. Teachers can design the kindergarten-family cooperation activities of "parents and teachers", and invite parents from some special industries to be assistants combining with needs of theme [15]. For example, parents working as traffic polices are invited to explain the traffic regulations and other general knowledge for preschool children, introduce the traffic situation of important junctions, etc., so as to enrich teaching contents for preschool children.

\section{CONCLUSION}

This article summarizes the first-line teaching experience through searching and reading the relevant literatures of the kindergarten-family cooperation mode in preschool education, and analyzes the two major influential factors of the professional quality of teachers and the family background of the preschool children aiming at the problems existing in the implementation of kindergarten-family cooperation mode in kindergartens, and then puts forward five major strategies for the effective operation of kindergarten-family cooperation mode.

(1)Teachers and parents learn the connotation of kindergarten-family cooperation to lay a theoretical foundation for the kindergarten-family cooperation.

(2)Teachers and parents unify the educational goal to speed up the development of preschool children.

(3)Teachers and parents should trust each other, communicate and exchange with each other timely.

(4)Teachers should design education and teaching activities which should be well-founded and suitable to actual circumstances.

(5)Teachers should make full use of potential educational resources of parents to enrich teaching contents.

\section{REFERENCES}

[1] Chaoxia Tuo. Problems of Kindergarten-Family Communication in kindergartens and solutions[J]. Xinkecheng (I), 2017 (2): 6.

[2] Nv Chen. Group of Teaching Assistants for the Growth of Preschool Children - New Kindergarten-Family Cooperation Mode [J]. Journal of Studies in Preschool Education, 2006 (4): 58-59.

[3] Lijuan Hu. Report on the Development of Preschool Education in China - Rural Preschool Education [M]. Beijing: Beijing Normal University Publishing House, 2013:262-277.

[4] Guichun Wang. Research on Status, Problems and Countermeasures of Kindergarten-Family Cooperation in Rural Kindergartens - a Case Study of Wuxi County, Chongqing [J]. Asia Pacific Education, 2016 (29): 257.

[5] Huanli Liu. Research on the Exploration of Micro-Course in Network Era [J]. Theory Horizon, 2016.14 (01): 135-137. 